\title{
Research on Teaching Reform of "Management" in Higher Vocational Education Based on Action Orientation
}

\author{
Yaoyan Wang
}

Yiwu Industrial \& Commercial College, Yiwu, 322000, China

\begin{abstract}
Keywords: action - oriented; higher vocational "management" course; teaching reform
\end{abstract}
\begin{abstract}
Action-oriented teaching is the rise of an advanced teaching method in the 1980s in Germany, which is now applied to the world's vocational education reform. Action-oriented teaching method is practical and interactive teaching method between teachers and students. This method is closely integrated with the "Management" course of higher vocational education, which can arouse the enthusiasm of students, and can also solve the problems in the process of practice, as a course of parallel development of learning and employment, to help students improve their career development plan and train students to apply professional competence. Based on this, this paper explores the relevant content of action-oriented teaching methods applied to higher vocational "management" course teaching reform.
\end{abstract}

\section{Introduction}

With the continuous development and progress of our society, more and more advanced enterprises in the current context of sustainable development and growth, so in expanding the employment strategy of the background, many vocational colleges have begun to improve student management capacity as At present, the main goal of development, although at this stage more employment opportunities, higher vocational students after graduation is also relatively easy to find a job, but it is precisely because of this situation, leading to the employment of vocational students is gradually declining . Thus, at present, China's vocational education "management" course of teaching students in the employment capacity of training is facing great challenges, these problems and the situation of our society's current economic situation has an impact, and put forward a feasible Teaching methods to improve the employment capacity of vocational students is imminent, through a lot of cases in the past that action-oriented teaching methods is such a method, and hope that this study can give the relevant educators to better use this method to bring some inspiration.

\section{A Brief Introduction to Action - oriented Teaching Method}

Action-oriented teaching methods, is the 1980s in Germany, the rise of a teaching means, now it has gradually become the world's vocational education reform. Action-oriented teaching refers to the teaching process, the students as the center of the organization of teaching curriculum, not only to guide students to learn knowledge also guide students to acquire knowledge and skills and skills to master, or learn to master the knowledge methods and processes [ 1]. Action-oriented teaching model all the design, implementation and evaluation of teaching activities are fully included in the realization of these professional activities to action or continuous action needs to have the environment. Action-oriented teaching focuses on the effective integration of action and learning, advocating action is learning, so that the process of cognitive learning students with future career positions in step. Teachers create an effective interaction with students in the context of the students through the process of the actual work of the future learning, students by learning process, explore, find and solve practical problems in vocational activities which not only participate in the whole process of teaching, but also for future career Post-generated new knowledge, immersive, accepted the experiential learning, and finally to reflect on the overall learning action to harvest results. Students through the appropriate learning, action and reflection links not only to their own knowledge literacy has been improved, but also to improve their ability to deal with practical 
problems, and finally get the future occupation activities need to master the ability and knowledge.

In the action-oriented teaching methods, students are learning the main body, but also successfully completed. I want to learn a series of changes and mobilize the enthusiasm of students and learning initiative. But at the same time, standing in higher vocational education, the overall goal of teaching is employment as a guide for the state and society to cultivate high-quality, strong ability of applied talents. This means that the need for teaching to practice teaching as the focus, focusing on training student's practical ability, in the study of related theory, students should pay attention to the application of practical knowledge and practical ability to solve real-life problems. The action-oriented teaching method is divided into the stages of information collection, work plan making, decision-making, implementation, post-implementation inspection and evaluation, which are combined with the shortcomings of low participation and unidirectional knowledge in higher vocational education. Based on the action-oriented teaching methods, the main position has always been given to students, while the final assessment methods need to be reflected in the overall quality of students. Therefore, action-oriented teaching methods to carry out teaching, students learn knowledge on the way, the student's concept, action, operation, future employment and cooperation ability to give a comprehensive training. Therefore, it is obvious that the importance and necessity of the action-oriented teaching method are widely popularized in the reform of higher vocational education.

\section{The Malpractice in the Teaching of Management in the Traditional Higher Vocational Education}

\subsection{The traditional concept of employment constraints}

Higher vocational students are the main body of employment, so students should strive to improve their overall quality and employability. But some students are more enthusiastic about online games, so that their studies were delayed, and their own professional knowledge (such as: 1) some students are not clear enough employment goals, pointing out that graduation is equivalent to unemployment; Is not enough solid; although some students can be fixed-point learning at school, but because of their lack of innovative ideas in learning, training for their ability to employ enough attention. Therefore, such students after graduation are not in the community to identify their own position. And at present, many vocational college students and parents are also confined to the traditional concept of employment, they pointed out that learning is to prevent students from early employment, and get a diploma can also facilitate future employment, as the real school To what, do not give too much attention, anyway, this future work will not constitute much of the impact of future employment is not a counterpart of the unknown, and so on, just want to find a job in the future Dangdang on the line [2]. Some people attach too much importance to graduate employment, pointed out that employment has an impact on people's lives, so the spirit of great pressure, once the reality with the ideal deviation, the heart will feel unbalanced, and even give up on themselves. All these circumstances make the teaching reform of the management course of traditional higher vocational education greatly hindered, and it also has great influence on the future employment of vocational college students.

\subsection{The use of materials emphasis on theory despise practice}

At present, most of the teaching materials used in the teaching of management in higher vocational schools pay more attention to the teaching of theoretical knowledge. Although some of the teaching materials have some cases to be added, some have made some changes in accordance with the requirements of task orientation and combination of work and study. In the form, pay attention to the surface of the article and ignore the substance, making the actual course content with the traditional textbooks are not much different. Especially for the "management" of the course, which is built on the basis of economic management theory, contact the status of economic market management and management activities of successful cases developed from the emerging science. The current internationalization process is accelerating, which also led to increasingly intense 
market competition. Based on the new business and market competition environment, society and enterprises are also more demand management of innovative talents. And to meet the rapid development of the market demand for the management of the elite requires the "management" course teaching a higher quality and level of teaching, which for the sustainable development of China's industry is of great practical value. However, the current "management" textbooks as a whole still seems to attach importance to the theory of neglect of practice, and teaching content and practical work there are many different, which is led to "Management" course teaching is mostly on the concept and theory, the lack of practical ability to teach, it is difficult to keep up with the international "management" the pace of rapid development, cannot be related to the development of students ability.

\section{Application of Action - oriented Teaching Method in the Teaching Reform of "Management" Course in Higher Vocational Colleges}

\subsection{And constantly improve the practice of education system}

Action-oriented teaching methods for teaching content, mainly based on a combination of action-based system, the action sequence for all aspects of imparting knowledge, which are all arranged according to normal action, natural process of action to be sorted, and thus from the student knowledge and understanding Look, it's a step-by-step process. This requires a sound practice education system as the basis, because the action system for various disciplines, such as "management" and the introduction of innovative marketing management relationship between, is not complete. The action-oriented teaching method based on the establishment of an integrated teaching system must be the same with the market management should correspond to the typical sequence of the same professional activities, or with a number of abstract induction and integration of professional activities corresponding to the process of building the same match with the market management vocational activities integrated Curriculum system, combined with interdisciplinary integrated teaching methods to cases and cultivate the ability to solve practical problems as the main content, enhance practical teaching, experience teaching links, the training content fully integrated into, to ensure that students' practical ability to strengthen all-round.

\subsection{Real - time updating of action - oriented teaching methods for teaching materials}

Nowadays, the teaching material of "management" course in many vocational colleges is not applicable to the implementation of action-oriented teaching method. Therefore, the education staff should try to be professional perspective, combined with their own teaching experience, with the vocational content of convergence, closely integrated with the professional engineering talent cultivation program, highlighting professional content, build up the training of professional competence, knowledge, quality and ability To-use, innovative and unique, intuitive and specific, efficient teaching courses, and based on the work of students after graduation job skills required to compile materials [3]. With the development of modern science and technology, three-dimensional textbooks also came into being. In order to achieve better teaching reform results, one need to add operational feasibility in the textbooks with high practical content and simple pictures, try to increase the number of successful cases; the second is the combination of advanced technical means such as multimedia so that three-dimensional textbooks more in line with action Teaching methods, the introduction of teaching resources to provide integrated programs, it can not only optimize the allocation and sharing of teaching resources, but also enable the teaching quality and level of a substantial increase in the promotion of teaching reform smoothly. In addition, teachers need to create a good teaching environment for students. Such as hard environment is mainly to cope with the layout of the classroom desks and chairs to be adjusted The traditional all students face the teacher into the students into different groups, and then surrounded by a circle around the teacher, which is more conducive to students to play a dominant position, but also conducive to cooperation between students exchanges; soft environment, teachers, students and schools Three aspects should actively change the concept. Such as the active organization of teacher training to enhance its 
teaching level and the effectiveness of teaching reform, teachers need to clear the teaching objectives and subjects, students need to actively cooperate with teachers teaching, divergent thinking, enhance their creativity and so on.

\section{Conclusion}

The current number of vocational students in the graduation, but also in the world outlook and the initial stage of development of life, once the decline in employment, it will affect the overall personality of students, resulting in many students self-esteem, conceited psychological, And even affect the social stability. There are many students because of poverty, graduated from vocational colleges, eager to quickly find a good job in order to subsidize the family, but the poor employment situation also led to students psychologically difficult to accept. Therefore, in view of the above content can be seen, vocational students after graduation employment problem, and national social stability and harmonious, rapid economic development has a great impact. Therefore, our government and universities, as well as employers can be said to have a huge responsibility, so the urgent need for a practical teaching methods to comprehensively enhance the employability of vocational students, making it a national and social needs Of course, this in the "management" course of teaching reform process is also applicable, it can be said that action-oriented teaching methods for graduates of the employment provides more opportunities and support.

\section{Acknowledgement}

This paper is one of the research findings of the project: Research on the reform of management courses teaching way which is based on action oriented”, the project number: kg2015815.

The advantages professionnal construction project of zhejiang Province in the 13th Five Year Plan - International economic and trade (Yiwu industrial and commercial college).

\section{References}

[1] The Course Reform of Ideological and Political Theory in Higher Vocational Education Based on the Action-oriented Mode - Taking "Ideological and Moral Cultivation and Legal Basis" as an Example [J]. Xiaoqing Guan, Xiaojing Chen. Tour Vocational Education (Journal of Tianjin Polytechnic) 03: 65-67, 2013

[2] Based on the action-oriented "NC machine tool mechanical parts assembly and maintenance" course teaching reform and practice [J] Denghong Huang. Vocational Education Research, 08: 86-88, 2013

[3] Active - oriented teaching of computer specialized courses in higher vocational education - the use of office equipment and maintenance courses as an example [J]. Dezhou Xia, Dongyu Xia.Journal of Hubei Industry Polytechnic, 04: 94-97, 2016

Zhejiang Province, 2015 annual higher education classroom teaching reform project "based on the action-oriented vocational management teaching reform research" research results, project number: kg2015815.

Zhejiang University "13th Five - Year" advantage of professional construction projects International Economics and Trade ( Yiwu Business Technology Vocational College). 